archives

of thermodynamics

Vol. 36(2015), No. 4, 65-76

DOI: $10.1515 /$ aoter-2015-0033

\title{
Vapordynamic thermosyphon - heat transfer two-phase device for wide applications
}

\author{
LEONARD VASILIEV ${ }^{a 1}$ \\ LEONID VASILIEV ${ }^{a}$ \\ ALEXANDER ZHURAVLYOV ${ }^{a}$ \\ ALEKSANDER SHAPOVALOV ${ }^{b}$ \\ ALEKSEI RODIN $^{b}$
}

a Porous Media Laboratory, Luikov Heat and Mass Transfer Institute of National Academy of Sciences of Belarus, P. Brovka Str. 15, 220072 Minsk, Belarus

${ }^{b}$ Department of Industrial Heat-Power Engineering and Ecology, P.O.Sukhoi State Technical University of Gomel, Octiabria Ave. 48, 246746 Gomel, Belarus

\begin{abstract}
Vapordynamic thermosyphon (VDT) is an efficient heat transfer device. The two-phase flow generation and dynamic interaction between the liquid slugs and vapor bubbles in the annular minichannel of the VDT condenser are the main features of such thermosyphon, which allowed to increase its thermodynamic efficiency. VDT can transfer heat in horizontal position over a long distance. The condenser is nearly isothermal with the length of tens of meters. The VDT evaporators may have different forms. Some practical applications of VDT are considered.
\end{abstract}

Keywords: Thermosyphon; Vapordynamic thermosyphon; Long horizontal condenser; Porous coating; Heat transfer intensification

\section{Nomenclature}

$$
\begin{aligned}
& H, h \quad-\quad \text { height, mm } \\
& \Delta h \quad-\quad \text { difference of level, } \mathrm{mm} \\
& P \quad-\text { pressure, } \mathrm{kPa}
\end{aligned}
$$

\footnotetext{
${ }^{1}$ Corresponding Author. E-mail: Leonard_Vasiliev@rambler.ru
} 

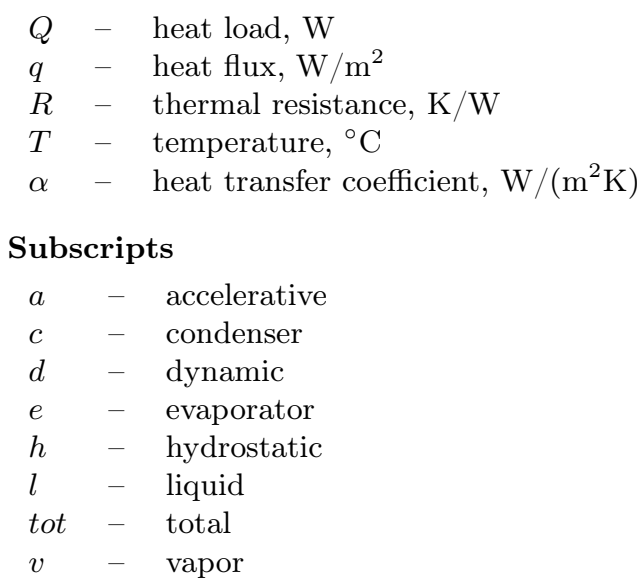

\section{Introduction}

In the up-to-date heat engineering autonomous two-phase devices such as heat pipes and thermosyphons are widely applied. Heat-conducting properties of these facilities are higher than those of the most heat-conducting metals. Two-phase conventional thermosyphons and loop thermosyphons have been developed for many years. Two-phase loop thermosyphons were used for several applications, such as electronics cooling [1-3], nuclear power plants [4], waste heat recovery [5], asphalt tank heating [6], miniature compressors cooling $[7,8]$ among many others. One of the variety of thermosyphons is a vapordynamic thermosyphon (VDT) developed in the Porous Media Laboratory of the Luikov Heat and Mass Transfer Institute (Minsk, Belarus). This device holds high heat-transmitting ability, low sensibility to a quantity of a working liquid, presence of a noncondensing gas, gives a possibility of various embodiments with an extensive zone of evaporation including bent or flexible modifications.

\section{Operating principle of VDT}

The name 'vapordynamic thermosyphon' is related to the dynamic interaction between the vapor bubbles and the liquid flow in the annular condenser of VDT (Fig. 1). The first principal distinction of VDT from conventional thermosyphons of the same diameter is related with its horizontally oriented annular condenser and the two phase flow of the working fluid inside it. They can transfer heat flow in horizontal position over a long distance. 


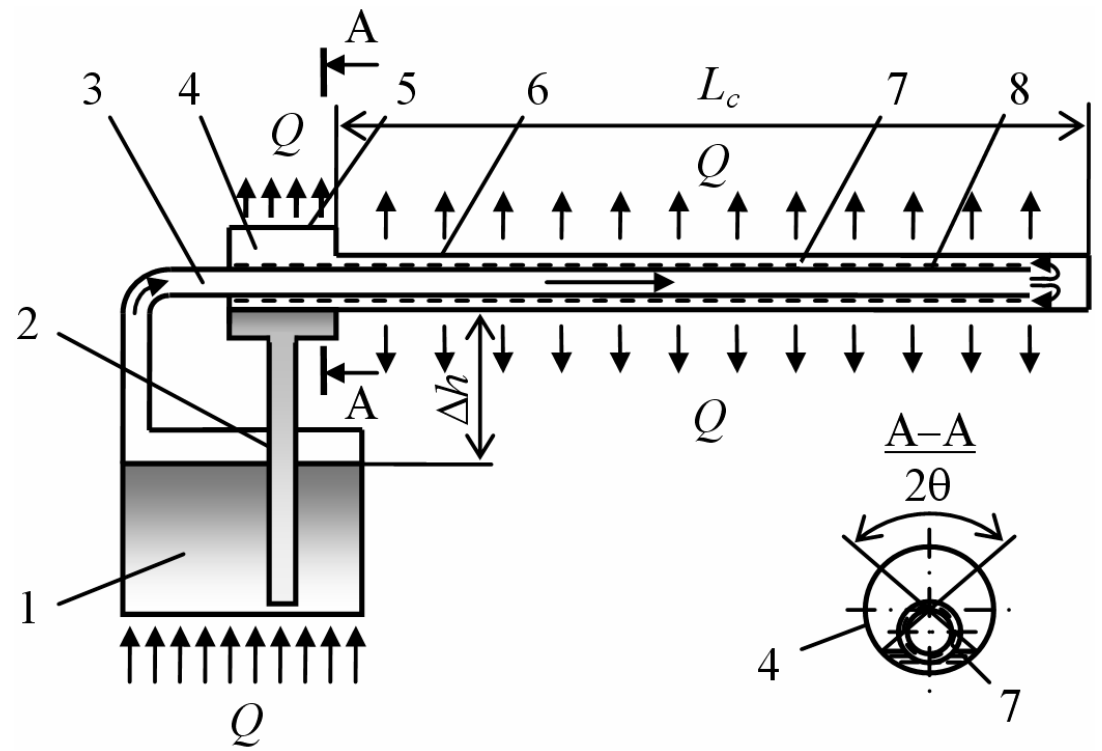

Figure 1: Vapordynamic thermosyphon: 1 - evaporator, 2 - liquid pipe, 3 - vapor pipe, 4 - compensation chamber, 5 - heat sink, 6 - condenser, 7 - annular channel, $\Delta h$ - hydrostatic pressure drop, 8 - porous coating [12].

The condenser is nearly isothermal with the length of tens of meters. The VDT evaporators may have different forms. The second principal distinction consists in the fact that the vapor flow and two-phase liquid flow are separated spatially (tube in tube heat exchanger). This makes it possible to avoid a negative hydrodynamic interaction between the opposite flows of the vapor and liquid typical for conventional thermosyphons [12].

Heat transfer from vapor to liquid occurs through a wall of a minichannel, which separates flows of a vapor and a condensate. Outer wall of VDT condenser is cooled at the expense of an intensive heat change with the ambient. Due to that fact a two-phase flow vapor - liquid is generated in annular gap. When two-phase flow moves along the annular channel the vapor concentration in unsaturated liquid gradually diminishes. An intensive heat transfer in the radial direction of a minichannel allows to support the temperature of a condenser surface close to isothermal. Vapor phase generated in VDT evaporator moves along the inner vapor exhaust pipe. In the terminal part of VDT vapor reverses and reenters the annular channel between inner and outer pipes of condenser where a further condensation is realized (Fig. 2). 


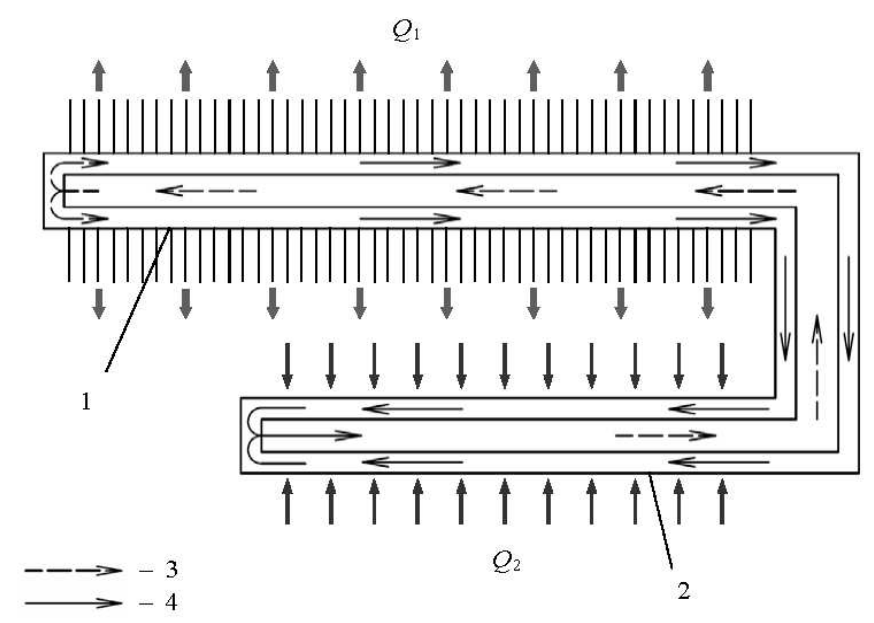

Figure 2: Circulation of a working medium with a change of phase in VDT with lengthy evaporator: 1 - condenser, 2 - evaporator, 3 - vapor, 4 - liquid, $Q_{1}$ and $Q_{2}$ - heat input and output, respectively.

The heat transfer intensification in VDT evaporators is related to the porous coating of the heat loaded surface which ensures a heat transfer enhancement up to 5 times compared to the plain tube thermosyphon. Furthermore it starts to work without a temperature overshoot typical for conventional thermosyphons.

The vapor generated in the VDT evaporator passes through the vapor pipe, and enter into the annular gap of the condensation zone, where it condenses. The vapor pipe is made from metal with high thermal conductivity. There is an intense radial heat transfer with phase change between the vapor pipe and the condenser envelope. The experimental data obtained on a flooded and partially flooded vapor pipe in confined space (annular channel from 0.2 to $2 \mathrm{~mm}$ thick) [9] testify the phenomena of micro heat pipe inside a porous coating of the vapor pipe and mini heat pipe in the annular gap between the porous coating and the condenser envelope. Visual analysis (glass condenser) and experimental results show, that such combination is favorable for the enhancement of the heat transfer in the VDT condenser. The procedure of heat and mass transfer in such annular mini channel is interesting to visualize to be sure in what way the vapor flow and vapor bubbles are interacting with the liquid flow (Fig. 3).

There are two options of the VDT condenser design:

- When the condenser hydraulic diameter is less than a capillary con- 


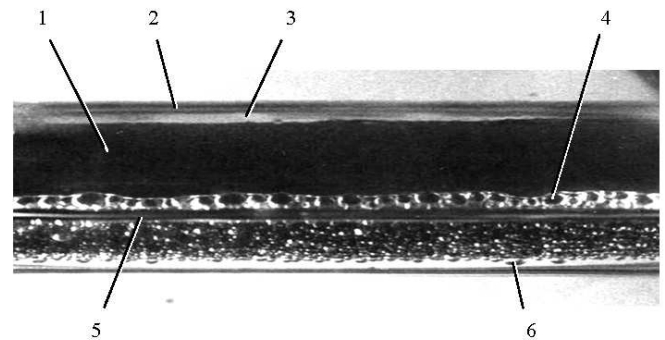

Figure 3: Visualization of the bubbles generation in the lower part of the porous coating immersed to the liquid pool (propane) in annular minichannel: 1 - vapor pipe (non-flooded part), 2 - glass tube, 3 - annular channel, 4 - vapor bubbles above a liquid - vapor interface, 5 - liquid - vapor interface, 6 - vapor bubbles on the flooded part of the vapor pipe.

stant, there is no fluid stratification in the channel. The vapor film condensation occurs on the entry part of the annular minichannel. The condensed liquid is moving along the annular minichannel to the VDT evaporator. The porous coating on the other surface of the vapor pipe saturated with the liquid provides a large surface of evaporation and enhances heat transfer inside the annular channel due to mini bubble generation in the pores. The dynamic pressure drop $\left(\Delta P_{d}\right)$ of vapor bubbles on the liquid is the additional force that induces liquid influx. Do they serve as mini compressors to push the two-phase flow along the condenser? In this case it is necessary to fulfill the condition

$$
\Delta P_{g}+\Delta P_{d}=\Delta P_{v}+\Delta P_{l},
$$

where $\Delta P_{l}$ denotes the pressure drop in the condenser.

- The condenser hydraulic diameter is more than the capillary constant. The stratification of the vapor and liquid flow occur in the annular minichannel. There is a liquid film condensation on the upper part of the condenser 6 (Fig. 1). The difference of the liquid/vapor interface level in the evaporation and condensation zones is $\Delta h=\left(h_{2}-h_{1}\right)$. The liquid returns into the evaporation zone through the liquid pipe 2 under the action of the hydrostatic pressure

$$
\Delta P_{h}=\left(\rho_{l}-\rho_{v}\right) \cdot g\left(h_{2}-h_{1}\right),
$$

where $\rho_{l}$ and $\rho_{v}$ are the liquid and vapor densities, $g$ is the gravitational acceleration, $h_{1}$ and $h_{2}$ are the heights of the liquid interface in the condenser and evaporator, respectively. 
The total pressure drop, $\Delta P_{t o t}$, is the summation of the pressure drop due to fluid flow in the evaporator, $\Delta P_{e}$, the vapor pipe, $\Delta P_{v}$, the condenser annular channel, $\Delta P_{c}$, and the liquid transport pipe, $\Delta P_{l}$, i.e.

$$
\Delta P_{\text {tot }}=\Delta P_{e}+\Delta P_{v}+\Delta P_{c}+\Delta P_{v}+P_{a},
$$

where $\Delta P_{e}$ denotes the pressure drop in the evaporator.

There is an intense heat transfer between the liquid, porous coating and the wall of the condenser. The difference of the height between the top of the vapor pipe and the liquid inside the condenser is denoted as $\Delta h$. To the optimal height $\Delta h=15-20 \mathrm{~mm}$ for propane, the heat transfer between the saturated vapor and the condenser wall is close to $45 \mathrm{~kW} /\left(\mathrm{m}^{2} \mathrm{~K}\right)$ at the heat load equal to $80 \mathrm{~kW} / \mathrm{m}^{2}$ [10].

The main VDT thermal parameters are: maximum heat load, $Q_{\max }$, heat flux in the evaporation zone, $q$, and thermal resistance, $R$. The VDT thermal resistance is determined as

$$
R=\left(T_{e}-T_{c}\right) / Q,
$$

where $T_{e}$ and $T_{c}$ are the average wall temperatures of the evaporator and the condenser, respectively, and $Q$ is the heat load. The VDT wall temperatures of the evaporator and the condenser as well as temperatures of vapor and condensate pipes are necessary to be known. Standard copper-constantan thermocouples with data acquisition unit were used for the measurements. When the thermosyphon exceeds the heat transfer limit $Q_{\max }$ due to high pressure drop, the condensate blocks part of the vapor pipe, increasing the overall thermal resistance of the system.

\section{$3 \quad$ Testing of vapordynamic thermosyphon with lengthy evaporator}

In cases of the elongated heat source it is reasonable to use VDT with lengthy evaporator due to ease of its assembly. For example, for heating/cooling solid sorption adsorbers of heat pumps or refrigerators it is convenient to use VDT evaporators/condensers disposed along the axes of the adsorber. The results of VDT testing with condenser $2.5 \mathrm{~m}$ long and outer diameter $24 \mathrm{~mm}$ (Fig. 4) and modelling of processes inside the VDT testify the high efficiency of such device.

The thermosyphon testing was carried out at various positions of VDT in space. The angle $\varphi$ of VDT inclination to the horizon (Fig. 5a) and 


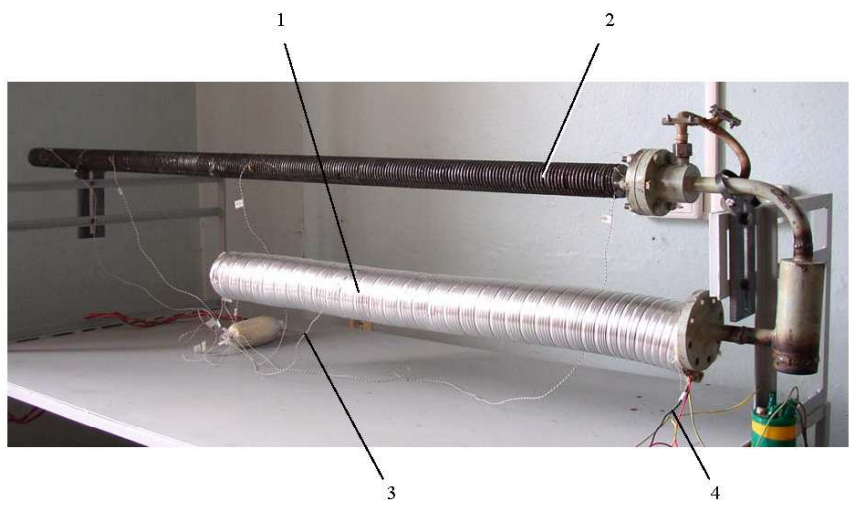

Figure 4: Vapordynamic thermosyphon on the test rig: 1 - evaporator with heat insulation, 2 - condenser, 3 - thermocouple conductor, 4 - cables of electric heater power supply.

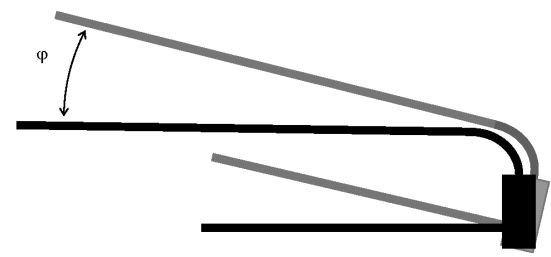

a)

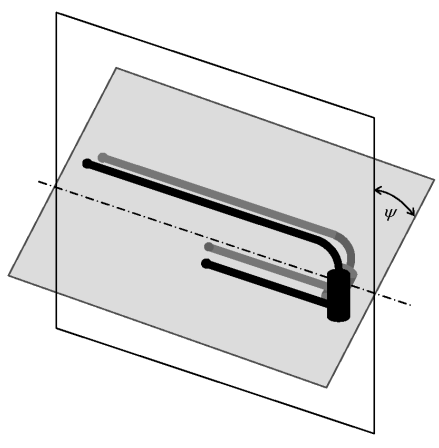

b)

Figure 5: Position VDT in a space: a) inclination of evaporator and condenser to the horizon, b) deflection of the plane of symmetry from the vertical position.

the angle $\psi$ of the VDT plane of symmetry deflection from the vertical position were changed (Fig. 5b) during the set of experiments. The thermal resistance $R=\left(T_{\text {init }}-T_{\text {fin }}\right) / Q$ of the evaporator and VDT versus heat flow is shown in Fig. 6. Parameters $T_{\text {init }}$ and $T_{\text {fin }}$ are the temperatures of initial and finite sections respectively in Kelvins $(\mathrm{K})$, and $Q$ is a heat flow in watts $(\mathrm{W})$.

As is apparent, after the start of steady operating regime of VDT that thermal resistances are minimal and the device features good heat-transfer characteristics. 


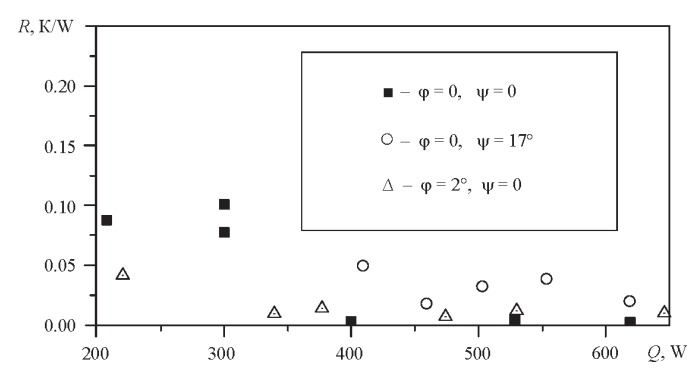

a)

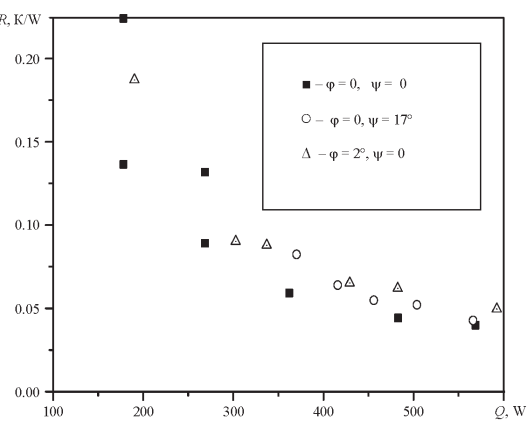

b)

Figure 6: Thermal resistances of an evaporator (a) and VDT (b).

\section{Heating devices based on vapordynamic thermosyphons}

Long vapordynamic thermosyphons with certain construction modifications are used for the floor heating in houses, timber drying, roof snow melting, etc. A VDT with long horizontal condenser $(10 \mathrm{~m})$ is shown in Fig. 7. An availability of an isothermal drying panel ensures a good quality of dried thermolabile materials and guarantees absence of local overheats. The VDT envelopes are made from stainless steel, the working fluids are water and propane. The VDT thermal resistance, $R$, as a function of heat load is shown in Fig. 8.

Vapordynamic thermosyphons can successfully be used as a thermal control system for snow thawing. Such VDT design are assigned to heat the railway switches (snow thawing) in winter (Fig. 9), green houses, floor in buildings and pavements. At the ambient temperature minus of $7-10^{\circ} \mathrm{C}$, the snowfall intensity of $100-150 \mathrm{~mm}$ and wind velocity $5-10 \mathrm{~m} / \mathrm{s}$ the vapordynamic heater ensures complete snow thawing. After the switch on of the VDT heater the snow between the stock and points rail disappears within one hour.

Also VDT can substitute electrical heaters and boilers, in snow melting devices for roads and sidewalks, etc. The VDT based recuperative heat exchangers development could be technology applicable to vapor-compression, direct-expansion, and chilled-water air-handling-unit coils; heat-powered desiccant dehumidification equipment (supermarket, ice-rink) and natatorium air-conditioning and dehumidification systems. This device was ap- 


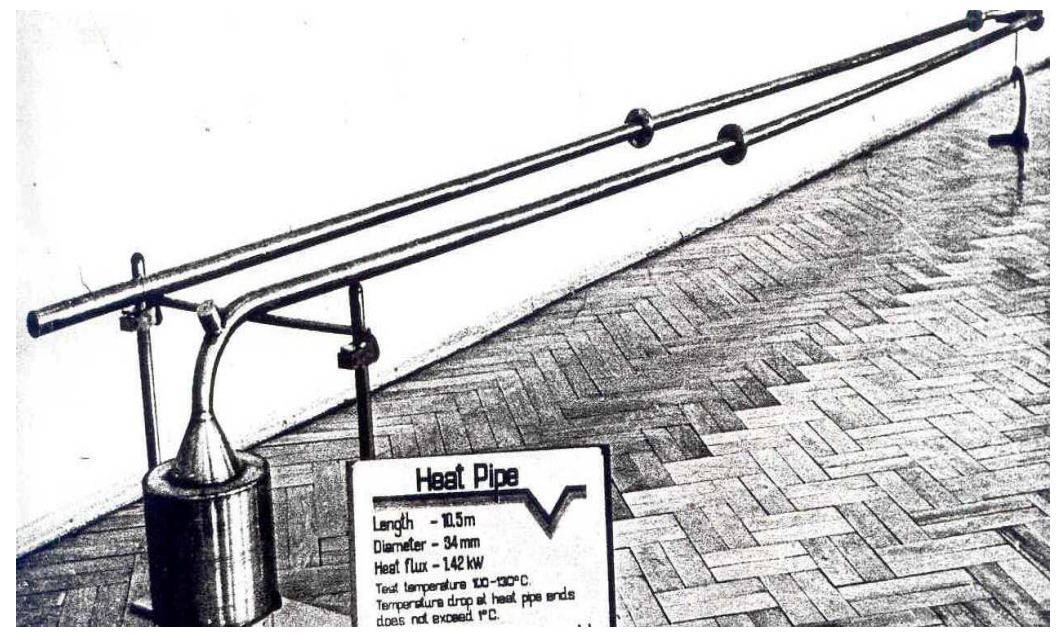

Figure 7: Vapordynamic thermosyphon, condenser length $-10 \mathrm{~m}$.

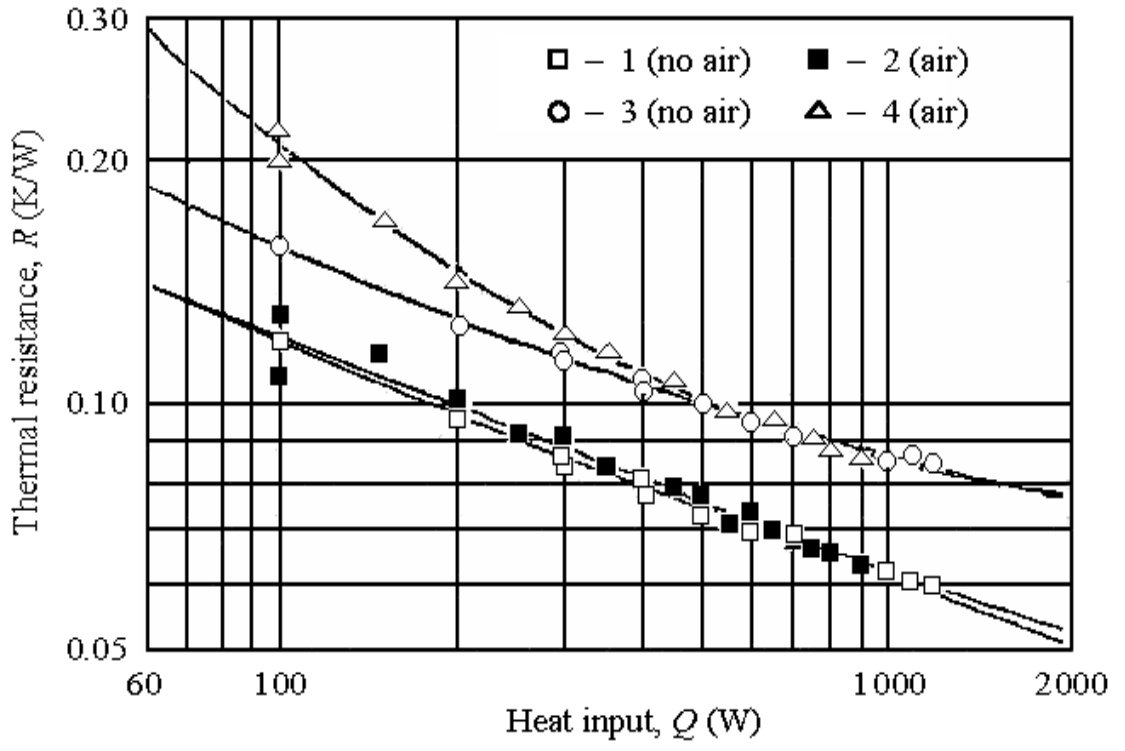

Figure 8: Thermal resistance $R$ of VDT as a function of heat load in watts: 1 - water, 2 - propane, 3 - water with air, 4 - propane with air in the gas trap.

plied for thermal coupling of solar collector and two adsorbers of the solid sorption cooler [11]. Such VDT of stainless steel has low thermal resistance 


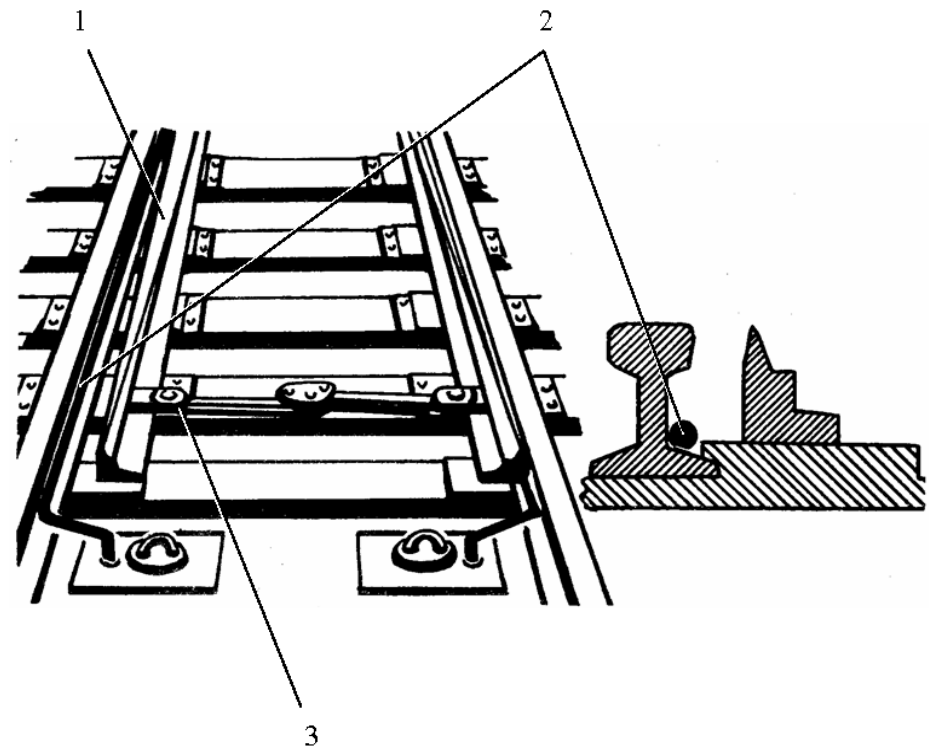

Figure 9: Application of VDT for snow melting (length $-4.5 \mathrm{~m}$, condenser diameter $16 \mathrm{~mm}$, heat flow - $2 \mathrm{~kW}): 1$ - tongue, 2 - condenser of VDT, 3 - mechanism of point operation.

( $R=0.01-0.05 \mathrm{~K} / \mathrm{W})$, the condenser length is $1 \mathrm{~m}$, the working fluid is water. The system of thermal management, based on VDT, is used to heat the sorbent material inside the adsorbers. VDT evaporators are disposed inside the glass vacuum tubes of solar collector. Two VDT condensers are placed inside adsorbers. Two vapor and liquid transport mini pipes are applied as the link between VDT evaporators and condensers. The natural mini gas burners are used as the alternative source of energy to heat the VDT evaporator at the night time. VDT condensers are switched on and off alternatively by valves. The constant heat flow (solar energy) in the VDT evaporators is transformed into intermittent heat flow in condensers.

\section{Conclusing remarks}

1. Horizontal vapordynamic thermosyphons (VDT) have a unique possibility to transfer the heat flow on long distances (tens of meters) with very highly uniform temperature distribution along the condenser due to the original design of the annular evaporator. 
2. Micro-, nanoporous coating of the evaporator and vapor pipe inside the condenser of VDT increases the intensity of heat transfer and substantially decreases its total thermal resistance. Vapordynamic thermosyphons with porous coating and small distance between the vapor pipe and condenser envelope (less than the capillary constant) can be used at the low gravity cases due to the dynamic bubble pressure on the liquid in the annular channel inside the VDT condenser.

3. Given device can successfully be used in various fields of technology both for heating and cooling and improve the quality of the industrial product. VDT can substitute electrical heaters and boilers in snow melting devices for roads and sidewalks, etc. The VDT based recuperative heat exchangers development could be technology applicable to vapor-compression, direct-expansion and chilled-water air-handlingunit coils; heat-powered desiccant dehumidification equipment (supermarket, ice-rink) and natatorium air-conditioning and dehumidification systems. VDT assisted solid sorption coolers and heaters are suggested and experimentally tested as thermal control system in solar refrigerators. Burning gas driven VDT are suggested for the solid sorption heat pumps with natural gas consumption savings, when compared to the traditional technologies.

Received 23 June 2015

\section{References}

[1] Garner S., Patel C.: Loop thermosyphons and their applications to high density electronics cooling. IPACK'01, The Pacific Rim/ASME Int. Electronic Packaging Techn. Conf. Exhib., Kauai, Hawaii. IPACK2001-15782, 2001.

[2] Khrustalev D.: Loop thermosyphons for cooling of electronics. In: Proc. 18th Semi-therm Symposium, 2002, 145-150.

[3] Khodabandeh R.: Pressure drop in riser and evaporator in an advanced two-phase thermosyphon loop. Int. J. Refrig. 28(2005), 5, 725-734.

[4] Sviridenko I., Shevelov D.: Autonomous thermosyphon system for WWER-1000 cooldown. Heat Pipe, Sci. Technol. 2(2011), 1-4, 145-159.

[5] Dube V., Akbarzadeh A., Andrews J.: The effects of non-condensable gases on the performance of loop thermosyphon heat exchangers. Appl. Therm. Eng. 24(2004), 2439-2451.

[6] Milanez F. H., Mantelli M.B.H.: Heat transfer limit due to pressure drop of a two-phase loop thermosyphon. Heat Pipe, Sci. Technol. 1(2010), 3, 237-250. 
[7] Possamai F.C., Setter I., Vasiliev L.L.: Miniature heat pipe as compressor cooling devices. Appl. Therm. Eng. 29(2009), 3218-3223.

[8] Aliakhnovich V.A., Kireichik D.G., Vasiliev L.L., Konev S.V., ZiKMAN A.B.: Cooling system for hermetic compressor based on the loop thermosyphon. In: Proc. 9th Minsk Int. Sem. Heat Pipes, Heat Pumps, Refrigerators, Power Sources 2(2011), 101-110.

[9] Vasiliev L., Zhuravlyov A., Shapovalov A., Litvinenko V.: Vaporization heat transfer in porous wicks of evaporators. Arch. Thermodyn. 25(2004), 3, 47-59.

[10] Vasiliev L., Zhuravlyov A., Shapovalov A.: Heat transfer enhancement in mini channels with micro/nano particles deposited on a heat-loaded wall. J. Enhanc. Heat Transf. 19(2012), 3, 13-24.

[11] Vasiliev L.L., Mishkinis D.A., Antukh A.A., Vasiliev L.L. Jr.: A solar-gas solid sorption refrigerator. Adsorption 7(2001), 149-161.

[12] Vasiliev L. et. al.: Heat-transfer device. U.S. Patent No. 45554 966, Nov. 26, 1985. 